\title{
Prevalence of anemia and nutritional status among HIV-positive children receiving antiretroviral therapy in Harar, eastern Ethiopa
}

This article was published in the following Dove Press journal:

HIVIAIDS - Research and Palliative Care

5 June 2015

Number of times this article has been viewed

\section{Zelalem Teklemariam' \\ Habtamu Mitiku' \\ Firehiwot Mesfin²}

'Department of Medical Laboratory Sciences, College of Health and Medical Sciences, Haramaya University, Harar, Ethiopia; ${ }^{2}$ School of Nursing and Midwifery, College of Health and Medical Sciences, Haramaya University, Harar, Ethiopia
Correspondence: Zelalem Teklemariam Department of Medical Laboratory Sciences, College of Health and Medical Sciences, Haramaya University, PO Box 33I, Harar, Ethiopia Email zelalemtmariam@yahoo.com
Purpose: Anemia and growth retardation are common manifestations of HIV-positive children, which threaten their lives. Therefore, this study tried to assess the burden of anemia and the nutritional status of HIV-positive children receiving antiretroviral therapy (ART) in eastern Ethiopa.

Patients and methods: A total of 108 records of children on ART followed up in Hiwot Fana Specialized University Hospital from 2007 to 2010 were retrospectively reviewed from November 1 to November 30, 2011.

Results: Approximately $54.4 \%$ of the children had been anemic before the initiation of their ART (at baseline): $7.8 \%$ were severely anemic and $44.7 \%$ were moderately anemic. These percentages were higher in preschool children than in school children (adjusted odds ratio [AOR]: 4.80 [95\% confidence interval $\{\mathrm{CI}\}: 1.96,11.75]$ ), and were higher in males than in females (AOR: 2.61 [95\% CI: 1.06, 6.45]). The prevalence of anemia was reduced to $39.2 \% 1$ year after initiation of ART. The increasing of hemoglobin values was highly significant for both zidovudine $($ AZT)- and stavudine $(\mathrm{d} 4 \mathrm{~T})$-based ART $(P<0.05)$. At baseline, $51.6 \%$ of the study subjects were underweight (weight-for-age $Z$ score less than -2 standard deviation [SD]); 49.1\% were stunted (height-for-age $\mathrm{Z}$ score less than $-2 \mathrm{SD}$ ); and 31.5\% were wasted (body mass index less than $-2 \mathrm{SD}$ ), which, after a year on ART, declined to $8.9 \%, 15.9 \%$, and $9.8 \%$, respectively.

Conclusion: There was high prevalence of anemia and growth failure among HIV-infected children in the study area. However, there was a decline after initiation of ART. Therefore, adherence counseling to strengthen the uptake of ART is recommended. Moreover, large-scale, prospective studies should be done to understand the magnitude and etiology of the problems with HIV-negative control groups.

Keywords: hemoglobin, underweight, stunting, wasting

\section{Introduction}

Human immunodeficiency virus (HIV) epidemic remains a serious challenge and continues to take its toll, particularly on vulnerable populations such as children. More than two out of three (68\%) adults, nearly $90 \%$ of HIV-infected children, and more than three-quarters (76\%) acquired immunodeficiency syndrome (AIDS) deaths in 2007 occurred in Sub-Saharan Africa.

Anemia is a common manifestation of pediatric HIV infection and is a significant negative predictor of survival. ${ }^{2,3}$ It occurs in $50 \%-90 \%$ of children living in both resource-limited and resource-rich settings. ${ }^{4}$ Many etiological factors probably contribute to the development of low iron status in HIV-infected children, such as reduced dietary intake, the quality of dietary iron, and altered iron absorption. ${ }^{5}$ 
Malnutrition is an important factor which might predict disease progression of HIV-infected individuals. It also results in higher risk of morbidity and mortality in both HIV-infected adults and children. Wasting and weight loss are common features of HIV infection, especially in resource-limited settings. In one review paper, approximately $40 \%-44 \%$ of adult wasting and $59 \%$ of child malnutrition were reported. ${ }^{6}$

Although there are studies on anemia and the nutritional status of HIV-infected children in Ethiopia, ${ }^{7}$ there have been no studies done in the eastern part of the country. Therefore, this study tried to assess the burden of anemia and the nutritional status of HIV-positive children receiving antiretroviral therapy (ART) in eastern Ethiopa.

\section{Methods}

\section{Study area, design, and study period}

A retrospective record review was conducted from November 1 to November 30, 2011, on HIV-positive children who attended for ART from 2007 to 2010 at the Hiwot Fana Specialized University Hospital. The hospital is located in Harar (the capital of Harari National Regional State), Ethiopia, which is $511 \mathrm{~km}$ from the city of Addis Ababa. The facility began providing ART service in 2007; since then, 183 children have attended to receive the treatment.

\section{Population}

The source population included all HIV-positive children who visited Hiwot Fana Specialized University Hospital for medical care. The study population included all HIV-positive children who received ART services in the ART unit of Hiwot Fana Specialized University Hospital.

\section{Sample size and sampling techniques}

All the children registered for ART in the hospital from the very beginning of the service provision were considered. Those who started ART clinically ( 20 children), those who dropped out early ( 15 children), those who transferred into the ART program ( 6 children), those who transferred out of the program early (12 children), and those whose records were incomplete (22 children) were excluded from the study; resulting in 108 children included in the study. Figure 1 flow chart shows how the study participants were selected.

\section{Data collection methods}

Data were collected by nurses who were working in the ART unit of the hospital. A checklist, which was developed from the children ART monitoring record book, was used to collect

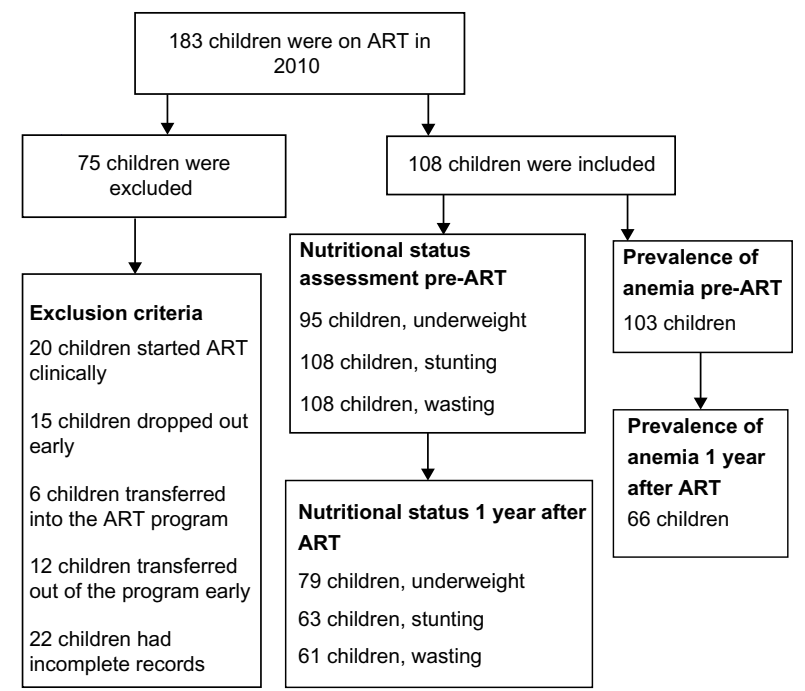

Figure I Flow chart depicting selection process for recruitment of study participants. Abbreviation: ART, antiretroviral therapy.

data from ART record books on sociodemographic status, hemoglobin, weight, height, CD4T cell count, type of ART regimens used, World Health Organization (WHO) clinical stages, tuberculosis (TB) screening results, and other items at baseline (before initiation of ART) and 1 year after ART initiation.

\section{Data analysis}

Data were entered into SPSS version 15, cleaned, and analyzed. Children aged less than 7 years were taken as preschool age, while those above 7 years were identified as school children. Anemia was defined as a hemoglobin concentration of less than $11 \mathrm{~g} / \mathrm{dL}$ for ages less than 5 years, $<11.5 \mathrm{~g} / \mathrm{dL}$ for ages 5-11 years, and less than $12 \mathrm{~g} / \mathrm{dL}$ for ages $12-14$ years. In addition, severe anemia was defined as a hemoglobin concentration of less than $7 \mathrm{~g} / \mathrm{dL}{ }^{8}$

The prevalence of anemia was determined as the proportion of anemic children. Immunodeficiency was classified into the three categories of "no evidence", "moderate", and "severe" immune suppression according to the 1994 revised classification system for HIV infection in children less than 13 years of age. ${ }^{9}$ Nutritional status of the children was analyzed using the WHO Anthroplus software and was expressed as standard deviation (SD). Weight-for-age Z score (WAZ), height-for-age Z score (HAZ), and body mass index (BMI) scores of less than -2 SD were considered as underweight, stunting, and wasting, respectively. Those children with a WAZ, HAZ, or BMI score less than $-3 \mathrm{SD}$ and between $-3 \mathrm{SD}$ and $-2 \mathrm{SD}$ were considered as severely and moderately underweight, stunting, and wasting, respectively. ${ }^{10,11}$ The prevalence of anemia was 
cross-tabulated with different study variables. Association of the variables was checked by using Pearson's chi-square and Fisher's exact tests, with $P$-values less than 0.05 at a $95 \%$ confidence interval (CI) taken as a statistically significant difference. Paired $t$-tests were used to compare an increase in hemoglobin and CD4 values after ART. Univariate and multivariate logistic regressions were employed to identify the possible risk factors of anemia.

\section{Ethical consideration}

This study obtained ethical clearance from the Institutional Health Research and Ethics Review Committee of the Haramaya University, Harar, Ethiopia. Information that was obtained during this study was kept confidential.

\section{Results}

\section{Study participants}

A total of 108 children participated in this study, of whom $55.6 \%$ were female, $50 \%$ were preschool children, and approximately $92.6 \%$ were urban dwellers. Their mean age was 7.0 years $(\mathrm{SD} \pm 3.2)$, with a range of $1.0-12.0$ years. On average, children attended ART for 40 months (SD \pm 16.0 ), with a range of 13.0-74.0 months. Few participants presented with smear-positive TB (13.9\%). Based on WHO clinical stages, $58.7 \%$ were in stage 3 , while $5.8 \%, 32.7 \%$, and $2.9 \%$ of them were in stages 1,2 , and 4, respectively. Approximately $89.2 \%$ (91/102) of them were immunosuppressed before initiation of ART, out of which $66.7 \%$ were severely and $22.5 \%$ were moderately immunosuppressed. Most of the children (63.9\%) were on a stavudine (d4T)-lamivudine (3TC)-nevirapine (NVP) ART regimen, while $4.6 \%, 23.2 \%$, and $8.3 \%$ of them were on d4T- 3TC-efavirenz (EFV), zidovudine (AZT)-3TC-NVP, and AZT-3TC-EFV, respectively. A total of 107 children had CD4 levels at baseline with mean of 336.78 (SD \pm 349.34 ). The overall level of adherence to ART was $99.1 \%$.

\section{Prevalence of anemia}

At baseline, the mean of the study subjects' hemoglobin was $10.7 \mathrm{~g} / \mathrm{dL}$ ( $\mathrm{SD} \pm 2.0$ ), ranging from 5.8 to $15.0 \mathrm{~g} / \mathrm{dL}$. The prevalence of anemia among children was $54.4 \%(56 / 103)$. Of anemic children, $44.7 \%$ were moderately and $7.8 \%$ were severely anemic. Anemia was higher among preschool than school children $(P<0.01)$. It was also higher among male, WHO clinical stages 3 and 4, TB-negative, urban, severely immunosuppressed, and cotrimoxazole treatment groups. However, the prevalence of anemia was not statistically significant with the above variables $(P>0.05)$ (Table 1$)$.
The prevalence of anemia was higher in those children who were underweight, and stunting but were not in no wasting group before the initiation of ART. However, it was not statistically significant when comparisons were made for the above nutritional assessment variables $(P>0.05)$ (Table 2).

The mean hemoglobin levels before and after initiation of ART were $11.1(\mathrm{SD} \pm 1.9)$ and $12(\mathrm{SD} \pm 1.8)$, respectively. The difference was statistically significant $(P<0.05)$, with $t=-5.84$ (CI: $-1.70,-8.37)$. The prevalence of anemia declined from $60.8 \%$ to $39.2 \% 1$ year after initiation of ART $(P<0.05)$. The prevalence of anemia 1 year after ART began was not related to AZT-based medication $(P>0.05)$. The average increases in hemoglobin upon treatment with AZT- and d4T-based ART were $1 \mathrm{~g} / \mathrm{dL}$ and $0.9 \mathrm{~g} / \mathrm{dL}$, respectively. The difference was statistically significant in those children with both AZT- and d4T-based treatments $(P<0.05)$. The mean CD4 count before and after initiation of ART was 378.76 (SD \pm 405.18 ) and 710.71 (SD \pm 475.83 ), respectively. The difference was statistical significant $(P<0.05)$, with $t=-4.39$ (CI: -484.85, -179.05) (Table 3).

Table I Prevalence of anemia before initiation of ART among HIV-infected children attending ART in Hiwot Fana Specialized University Hospital, Harar, eastern Ethiopa, 20I I

\begin{tabular}{|c|c|c|c|}
\hline Variables & $\begin{array}{l}\text { Anemic, } \\
\text { N (\%) }\end{array}$ & $\begin{array}{l}\text { Non-anemic, } \\
\text { N (\%) }\end{array}$ & $P$-value \\
\hline \multicolumn{4}{|l|}{ Age (years) } \\
\hline Preschool $(<7)$ & $36(35)$ & $14(13.6)$ & \multirow[t]{2}{*}{$<0.01$} \\
\hline School $(\geq 7)$ & $20(19.4)$ & $33(32.0)$ & \\
\hline \multicolumn{4}{|l|}{ Sex } \\
\hline Male & $30(29.1)$ & $17(16.5)$ & \multirow[t]{2}{*}{0.07} \\
\hline Female & $26(25.2)$ & $30(29.2)$ & \\
\hline \multicolumn{4}{|l|}{ Residence } \\
\hline Urban & $5 I(49.5)$ & $44(42.7)$ & \multirow[t]{2}{*}{0.63} \\
\hline Rural & $5(4.9)$ & $3(2.9)$ & \\
\hline \multicolumn{4}{|l|}{ WHO clinical stage } \\
\hline $\mathrm{I}$ and 2 & $23(23.2)$ & $15(15.2)$ & \multirow[t]{2}{*}{0.35} \\
\hline 3 and 4 & $31(31.3)$ & $30(30.3)$ & \\
\hline \multicolumn{4}{|c|}{ Tuberculosis infection } \\
\hline Positive & $8(7.8)$ & $7(6.8)$ & \multirow[t]{2}{*}{0.51} \\
\hline Negative & $49(47.6)$ & $39(37.9)$ & \\
\hline \multicolumn{4}{|c|}{ Cotrimoxazole treatment } \\
\hline Yes & $55(53.4)$ & $47(45.6)$ & \multirow[t]{2}{*}{$1.00 *$} \\
\hline No & $\mathrm{I}(\mathrm{I} .0)$ & $0(0 \%)$ & \\
\hline \multicolumn{4}{|l|}{ Immunosuppression } \\
\hline No evidence & $4(4.1)$ & $7(7.2)$ & \multirow[t]{3}{*}{0.26} \\
\hline Moderate & II (II.3) & $12(12.4)$ & \\
\hline Severe & $38(25.8)$ & $25(39.2)$ & \\
\hline
\end{tabular}

Note: *Fisher's exact test result.

Abbreviations: ART, antiretroviral therapy; HIV, human immunodeficiency virus; $\mathrm{N}$, number of patients; WHO, World Health Organization. 
Table 2 Prevalence of anemia in relation to nutritional status before initiation of ART among HIV-infected children attending ART clinics at Hiwot Fana Specialized University Hospital, Harar, eastern Ethiopa, 201I

\begin{tabular}{llll}
\hline Variables & $\begin{array}{c}\text { Anemic, } \\
\text { N (\%) }\end{array}$ & $\begin{array}{l}\text { Non-anemic, } \\
\text { N (\%) }\end{array}$ & P-value \\
\hline $\begin{array}{llll}\text { Weight-for-age Z score } \\
\quad \text { Underweight }\end{array}$ & $29(32.2)$ & $19(21.1)$ & 0.44 \\
$\quad$ Not underweight & $22(24.4)$ & $20(22.2)$ & \\
$\begin{array}{l}\text { Height-for age Z score } \\
\quad \text { Stunting }\end{array}$ & $31(30.1)$ & $22(21.4)$ & 0.39 \\
$\quad$ No stunting & $25(24.3)$ & $25(24.3)$ & \\
$\begin{array}{l}\text { Body mass index } \\
\quad \text { Wasting }\end{array}$ & $15(14.6)$ & $17(16.5)$ & 0.31 \\
$\quad$ No wasting & $4 I(39.8)$ & $30(29.1)$ & \\
\hline
\end{tabular}

Abbreviations: ART, antiretroviral therapy; HIV, human immunodeficiency virus; $\mathrm{N}$, number of patients.

\section{Nutritional status}

The prevalence of underweight children (WAZ less than -2 SD) was 51.6\% (49/95) at baseline (before initiation of ART), in which $28.4 \%$ (27/95) were severely underweight, and $23.2 \%(22 / 95)$ were moderately underweight. More females (30.5\% [29/95]) were underweight than males $(P=0.27)$. The prevalence of stunting (HAZ less than -2 SD was $49.1 \%(53 / 108)$ of the children, out of which $34.3 \%$ (37/108) were severely stunted. More females $(28.7 \%$ $[31 / 108])$ were stunted than males $(P=0.55)$. Approximately $31.5 \%$ of children $(34 / 108)$ were wasted (BMI less than -2 $\mathrm{SD})$, out of which $13.9 \%$ (15/108) were severely wasted.

Table 3 Prevalence of anemia and average hemoglobin level before and I year after initiation of ART among HIV-infected children attending ART clinics in Hiwot Fana Specialized University Hospital, Harar, eastern Ethiopa, 20II

\begin{tabular}{|c|c|c|c|}
\hline Variables & $\begin{array}{l}\text { Before } \\
\text { ART, } \\
\text { N=66 }\end{array}$ & $\begin{array}{l}\text { One year } \\
\text { after ART, } \\
N=66\end{array}$ & $P$-value \\
\hline Anemic & 31 (60.8\%) & 20 (39.2\%) & 0.04 \\
\hline \multicolumn{4}{|l|}{ Anemia } \\
\hline AZT-based & & 7 (10.6\%) & 0.85 \\
\hline d4T-based & & 13 (19.7\%) & \\
\hline \multicolumn{4}{|l|}{ Mean hemoglobin } \\
\hline $\begin{array}{l}\text { AZT-based }(\mathrm{N}=22) \text {, } \\
\text { mean }(\mathrm{SD})\end{array}$ & $\begin{array}{l}\text { II } \\
(\mathrm{SD} \pm 2.0)\end{array}$ & $\begin{array}{l}12 \\
(\mathrm{SD} \pm 1.5)\end{array}$ & 0.04 \\
\hline $\begin{array}{l}\text { d4T-based }(\mathrm{N}=44) \text {, } \\
\text { mean }(\mathrm{SD})\end{array}$ & $\begin{array}{l}\text { II.I } \\
(\mathrm{SD} \pm 1.9)\end{array}$ & $\begin{array}{l}12 \\
(S D \pm I .7)\end{array}$ & $<0.01$ \\
\hline \multicolumn{4}{|l|}{ Mean CD4 count } \\
\hline $\begin{array}{l}\text { AZT-based }(\mathrm{N}=12) \\
\text { mean }(\mathrm{SD})\end{array}$ & $\begin{array}{l}226.4 I \\
(S D \pm \mid 34.4 I)\end{array}$ & $\begin{array}{l}598.25 \\
(S D \pm 464.45)\end{array}$ & 0.01 \\
\hline $\begin{array}{l}\text { d4T-based }(\mathrm{N}=27) \\
\text { mean }(\mathrm{SD})\end{array}$ & $\begin{array}{l}508.15 \\
(S D \pm 523.15)\end{array}$ & $\begin{array}{l}760.70 \\
(S D \pm 480.84)\end{array}$ & 0.02 \\
\hline
\end{tabular}

Abbreviations: ART, antiretroviral therapy; AZT, zidovudine; d4T, stavudine; HIV, human immunodeficiency virus; $\mathrm{N}$, number of patients; SD, standard deviation.
More females $(20.4 \%$ [22/108]) were wasted than males $(P=0.20)$ (Table 4).

The prevalence of underweight children declined to $8.9 \% 1$ year after initiation of ART. Exactly $6.3 \%$ of children $(5 / 79)$ were severely underweight. In addition, approximately $15.9 \%(10 / 63)$ and $9.8 \%(6 / 48)$ of the children were stunted and wasted, respectively. The difference was statistically significant for underweight children and stunting $(P<0.05)$ (Table 4).

\section{Risk of anemia}

In univariate analyses, the odds of being anemic were 4.25 times higher in preschool children compared to school children. Those variables with $P$-values less than 0.3 , such as age, sex, and immunosuppression, were included for multivariate analysis. In this analysis, the odds of being anemic were 4.80 times higher in preschool children compared to school children. In addition, the odds of being anemic were 2.61 times higher in males compared to females (Table 5).

\section{Discussion}

Before initiation of ART in children, anemia in this study (54.4\%) was almost as prevalent in the subjects as in a similar study done in Jimma, Ethiopia $(53.1 \%),{ }^{7}$ but it was less common than in reports from India (66\%) and South Africa (73\%). ${ }^{12,13}$ Prevalence of anemia was higher among the preschool children in the current study. This finding was similar to findings in other similar studies. ${ }^{4,12,13}$ This might be due to the increased growth requirements of preschool children, as described by Shet et al. ${ }^{12}$ Anemia is caused by different ethological agents, which include nutrient deficiency,

Table 4 Prevalence of underweight children, stunting, and wasting before and I year after the initiation of ART among HIVinfected children attending ART clinics in Hiwot Fana Specialized University Hospital, Harar, eastern Ethiopa, 20I I

\begin{tabular}{|c|c|c|c|}
\hline Variables & $\begin{array}{l}\text { Before } \\
\text { ART, } \\
\text { N (\%) }\end{array}$ & $\begin{array}{l}\text { One year } \\
\text { after ART, } \\
\mathbf{N}(\%)\end{array}$ & $P$-value \\
\hline \multicolumn{4}{|c|}{ Weight-for-age Z score } \\
\hline Underweight & $42(53.2)$ & $7(8.9)$ & $0.01 *$ \\
\hline Not underweight & $37(46.8)$ & $72(91.1)$ & \\
\hline \multicolumn{4}{|c|}{ Height-for-age Z score } \\
\hline Stunted & $29(46.0)$ & $10(15.9)$ & 0.00 \\
\hline Not stunted & $34(54.0)$ & $53(84.1)$ & \\
\hline \multicolumn{4}{|l|}{ Body mass index } \\
\hline Wasted & $21(34.4)$ & $6(9.8)$ & $0.4 I^{*}$ \\
\hline Not wasted & $40(65.6)$ & $55(90.2)$ & \\
\hline
\end{tabular}

Note: *Fisher's exact test result

Abbreviations: ART, antiretroviral therapy; HIV, human immunodeficiency virus; $\mathrm{N}$, number of patients. 
Table 5 Univariate and multivariate analysis for risk factors of anemia at baseline among HIV-infected children attending ART clinics in Hiwot Fana Specialized University Hospital, Harar, eastern Ethiopa, 20I I

\begin{tabular}{|c|c|c|c|c|}
\hline Variables & $\begin{array}{l}\text { Crude odds ratio } \\
\text { ( } 95 \% \text { confidence interval) }\end{array}$ & $P$-value & $\begin{array}{l}\text { Adjusted odds ratio } \\
\text { ( } 95 \% \text { confidence interval) }\end{array}$ & P-value \\
\hline \multicolumn{5}{|l|}{ Age (years) } \\
\hline School $(\geq 7)$ & I & & I & \\
\hline Preschool $(<7)$ & $4.24(1.85,9.73)$ & 0.00 & $4.80(1.96,11.75)$ & 0.00 \\
\hline \multicolumn{5}{|l|}{ Sex } \\
\hline Female & I & & I & \\
\hline Male & $2.04(0.92,4.50)$ & 0.08 & $2.61(1.06,6.45)$ & 0.04 \\
\hline \multicolumn{5}{|l|}{ Immunosuppression } \\
\hline No evidence & I & & 1 & \\
\hline Immunosuppressed & $2.32(0.63,8.5 \mathrm{I})$ & 0.21 & $2.0(0.47,8.51)$ & 0.35 \\
\hline
\end{tabular}

Abbreviations: ART, antiretroviral therapy; HIV, human immunodeficiency virus.

immunosuppression of erythropoiesis, drug side effects, opportunistic infections, HIV-associated malignancies, and other factors. ${ }^{4,5,14}$ Anemia is also the major factor that reduces the survival odds of HIV-infected children. ${ }^{2,3}$ Therefore, it is advisable to assess and tackle predisposing factors toward anemia in HIV-infected children.

There was a high prevalence of underweight, stunting, and wasting in children before the initiation of ART in this study. This is in agreement with some other reports. ${ }^{14-16}$ This result might be due to direct consequences of the HIV infection, secondary clinical illnesses associated with HIV, a function of the child's adverse environment, or a combination of these factors, as described by Shet et al. ${ }^{12}$ The high prevalence of underweight, stunting, and wasting in children could not be correlated with magnitude of anemia in this study. However, it was correlated in one other study. ${ }^{12}$

The prevalence of anemia, underweight children, stunting, and wasting declined 1 year after the initiation of ART. The positive effects of using ART on the nutritional and anemic status of children has been published in other studies., ${ }^{7,14-19}$ The mean increase in hemoglobin values after initiation of ART was statistically significant in both AZT- and d4Tbased groups. This result is similar to a study from Jimma, Ethiopia. ${ }^{7}$ The mean increase in hemoglobin values in our study were $1 \mathrm{~g} / \mathrm{dL}$ and $0.9 \mathrm{~g} / \mathrm{dL}$ in the AZT- and d4T-based groups, respectively. This result is different when compared to $0.8 \mathrm{~g} / \mathrm{dL}$ and $3.5 \mathrm{~g} / \mathrm{dL}$ increases in AZT- and d4T-based groups in Jimma, Ethiopia, ${ }^{7}$ which may be because those children's mean hemoglobin was lower before initiation of ART. The difference might also be due to differences in study design and sampling techniques.

\section{Limitations of the current study}

Those children with missing data were not included in this study, and this exclusion can be a potential limitation in a retrospective study. Thus, the true prevalence of anemia and malnutrition in our study area might not be reflected. In addition, the effect of opportunistic infections and nutritional support/supplementation on anemia, and the nutritional status of HIV-infected children were not assessed in this study.

\section{Conclusion}

In general, there was high prevalence of anemia and growth failure among the HIV-infected children in the Hiwot Fana Specialized University Hospital. They declined after initiation of ART, which highlights the importance of the treatment. Unfortunately, the problems in HIV-infected children still need attention. Therefore, as part of HIV-infected children's care, health professionals should routinely diagnose hematological and nutritional parameters before and after the initiation of ART. Adherence counseling to strengthen the uptake of ART is also recommended. In addition, to plan appropriate interventions and understand the magnitude and the risk factors associated with anemia and nutritional status in HIVinfected children, further large-scale, prospective studies that include HIV-negative controls are recommended.

\section{Acknowledgments}

We acknowledge the Haramaya University Research and Publication Office for funding. Our thanks also extend to the Institutional Health Research and Ethics Review Committee of the Haramaya University for facilitating ethical clearance. We thank Muna Abdela for helping with data entry.

\section{Author contributions}

ZT and FM participated in proposal writing, data collection, analysis, interpretation, and critical revision of the manuscript. HM participated in data analysis, interpretation, and critical revision of the manuscript. All authors read and approved the final manuscript. 


\section{Disclosure}

The authors report no conflicts of interest in this work.

\section{References}

1. Joint United Nations Programme on HIV/AIDS, World Health Organization. AIDS Epidemic Update: December 2007. Geneva: World Health Organization; 2007.

2. Hilgartner M. Hematologic manifestations in HIV-infected children. J Pediatr. 1991;119:S47-S49.

3. Tovo PA, de Martino M, Gabiano C, et al. Prognostic factors and survival in children with perinatal HIV-1 infection. Lancet. 1992;339: 1249-1253.

4. Calis JC, van Hensbroek MB, de Haan RJ, Moons P, Brabin BJ, Bates I. HIV-associated anemia in children: a systematic review from a global perspective. AIDS. 2008;22(10):1099-1112.

5. Olivares M, Walter T, Hertrampf E, Pizarro F. Anaemia and iron deficiency disease in children. Br Med Bull. 199;55:534-543.

6. Growth Failure in HIV-infected Children. Consultation on Nutrition and HIV/AIDS in Africa: Evidence, Lessons and Recommendations for Action. Arpadi SM; Geneva: World Health Organization; 2005. Available from: http://www.who.int/nutrition/topics/Paper\%20Number\%204\%20-\%20 Growth\%20failure.pdf. Accessed June 25, 2010.

7. Abebe M, Alemseged F. Hematologic abnormalities among children on HAART in Jimma University Specialized hospital, Southwestern Ethiopia. Ethiop J Health Sci. 2009;19(2):83-89.

8. Iron Deficiency Anaemia: Assessment, Prevention, and Control. A Guide for Programme Managers. Geneva: World Health Organization; 2001. Available from: http://apps.who.int/iris/bitstream/10665/66914/1/ WHO_NHD_01.3.pdf. Accessed May 7, 2015.

9. 1994 Revised Classification System for Human Immunodeficiency Virus Infection in Children Less Than 13 Years of Age. Official Authorized Addenda: Human Immunodeficiency Virus Infection Codes and Official Guidelines for Coding and Reporting ICD-9-CM. MMWR. Georgia: Centers for Disease Control and Prevention 1994;43 (No RR-12):1-10. Available from: http://www.cdc.gov/mmwr/PDF/rr/rr4312.pdf. Accessed May 23, 2012.
10. WHO Child Growth Standards. Geneva: World Health Organization; 2006. Available from: http://www.who.int/childgrowth/standards/ Technical_report.pdf?ua=1. Accessed May 8, 2015.

11. Physical Status, the Use and Interpretation of Anthropometry. Technical Report Series No 854. Geneva: World Health Organization; 1995. Available from: http://whqlibdoc.who.int/trs/WHO_TRS_854.pdf?ua=1. Accessed May 8, 2015.

12. Shet A, Mehta S, Rajagopalan N, et al. Anemia and growth failure among HIV-infected children in India: a retrospective analysis. $B M C$ Pediatr. 2009;9:37.

13. Eley BS, Sive1 AA, Shuttleworth M, Hussey GD. A prospective, crosssectional study of anaemia and peripheral iron status in antiretroviral naive, HIV-1 infected children in Cape Town, South Africa. BMC Infect Dis. 2002;2:3.

14. Shet A, Arumugam K, Rajagopalan N, et al. The prevalence and etiology of anemia among HIV-infected children in India. Eur J Pediatr. 2012;171(3):531-540.

15. Arpadi SM. Growth failure in children with HIV infection. $J$ Acquir Immune Defic Syndr. 2000;25(Suppl 1):S37-S42.

16. Steenkamp L, Dannhauser A, Walsh D, et al. Nutritional, immune, micronutrient and health status of HIV-infected children in care centres in Mangaung. S Afr J ClinNutr. 2009;22(3):131-136.

17. Kabue MM, Kekitiinwa A, Maganda A, et al. Growth in HIV-infected children receiving antiretroviral therapy at a pediatric infectious diseases clinic in Uganda. AIDS Patient Care STDS. 2008;22(3): 245-251.

18. Nachman SA, Lindsey JC, Moye J, et al; Pediatric AIDS Clinical Trials Group 377 Study Team. Growth of human immunodeficiency virus infected children receiving highly active antiretroviral therapy. Pediatr Infect Dis J. 2005;24(4):352-357.

19. Guillén S, Ramos JT, Resino R, Bellón JM, Muñoz MA. Impact on weight and height with the use of HAART in HIV-infected children. Pediatr Infect Dis J. 2007;26(4):334-338.
HIV/AIDS - Research and Palliative Care

\section{Publish your work in this journal}

HIV/AIDS - Research and Palliative Care is an international, peerreviewed open-access journal focusing on advances in research in HIV, its clinical progression and management options including antiviral treatment, palliative care and public healthcare policies to control viral spread. The journal welcomes original research, basic science,

\section{Dovepress}

clinical \& epidemiological studies, reviews \& evaluations, expert opinion \& commentary, case reports \& extended reports. The manuscript management system is completely online and includes a very quick and fair peer-review system. Visit http://www.dovepress.com/ testimonials.php to read real quotes from published authors. 